\title{
DO MATERIAL AO IMAGINÁRIO: UMA ANÁLISE INTERPRETATIVA DAS PERCEPÇÕES AMBIENTAIS DOS CONDUTORES DO PARQUE NACIONAL DO ITATIAIA (RJ)
}

Ana Cristina Figueira de Almeida ${ }^{1}$

Najda Maria Castilho da Costa ${ }^{2}$

Resumo: Este artigo objetiva avaliar a percepção ambiental dos condutores do Parque Nacional do Itatiaia. A metodologia baseia-se no modelo de Whyte (1977, p.78), com a coleta de dados obtida através de entrevista não padronizada e questionários que foram aplicados a 15 condutores do Parque, em dias e horários diversificados, no período de agosto a outubro de 2016. Os resultados apontaram que, apesar de o grupo perceber mais marcadamente as áreas mais visitadas, estes possuem um grande laço afetivo com o espaço e o seu entorno, resultando na percepção dos impactos e na posterior escolha de cuidados, como a estruturação do espaço físico e a conservação e preservação do espaço natural, associadas às atividades principais de estudo e trabalho.

Palavras-chave: Percepção Ambiental; Paisagem; Condutores.

1Universidade Estadual do Rio de Janeiro. E-mail: cristinafalmeida@outlook.com.

2 Universidade Estadual do Rio de Janeiro. E-mail: nadjacastilho@oi.com.br

Revbea, São Paulo, V. 12, No 2: 229-250, 2017.

revista brasileira educação ambiental 


\section{Introdução}

O meio ambiente é o resultado de interações múltiplas e complexas, mutáveis e dinâmicas entre o espaço natural e a ação social que permitem a construção do sentido de localidade, territorialidade, identidade, pertencimento e de contextualização para os sujeitos individuais e os coletivos (LOUREIRO, 2004, p 224). Neste sentido, a educação ambiental torna-se uma importante ferramenta.

Um dos objetivos da Educação Ambiental é estabelecer e reforçar o vínculo de pertencimento à natureza, explorando relações entre identidade, cultura e natureza, além de reconhecer os vínculos entre diversidade biológica e diversidade cultural e apreciar esta diversidade (SAUVÉ, 2003, p.20).

As diferentes formas como os seres humanos compreendem e valorizam a natureza estão diretamente influenciadas por seus contextos socioculturais; assim, as relações estabelecidas com o mundo não humano divergem entre culturas, momentos históricos e mesmo entre indivíduos dentro da mesma cultura. Desse modo, as percepções sobre a natureza são histórica e culturalmente determinadas e o reconhecimento dessas diferenças pode auxiliar na análise crítica sobre as maneiras de lidar com o mundo natural (HOEFFEL; FADINI, 2007, p. 253-262).

As ações em Educação Ambiental devem se adaptar a cada realidade, trabalhando questões específicas de cada lugar em respeito à cultura, aos hábitos, aos aspectos psicológicos, às características biofísicas, socioeconômicas e históricas de cada localidade (GUIMARÃES, 1995, p.107). Neste sentido, o estudo da percepção ambiental torna-se primordial para compreender as inter-relações dos seres humanos com o ambiente para o desenvolvimento de forma efetiva de ações de Educação Ambiental que colaborem na solução de conflitos e problemas socioambientais e na valorização das potencialidades locais.

A percepção do meio ambiente é uma forma de tentar entender e explicar as relações entre o ser humano e o ambiente, buscando a compreensão de como uma pessoa, seja individualmente, ou como parte de um grupo, percebe seu entorno e quais os valores que estão implícitos quando toma determinadas decisões (DI TULLIO, 2005, p.172).

Para analisar as relações do ser humano com o meio, é necessário compreender, como está estruturado esse espaço percebido na mente das pessoas, ou seja, como ocorre a construção das imagens mentais (OLIVEIRA, 2006, p.5-22)

Tuan (1980, p.126) se referia ao termo Topofilia como atração do ser humano aos aspectos físicos, especialmente paisagísticos, de um determinado ambiente, representando a ligação afetiva que as pessoas apresentam com um ambiente qualquer, natural ou construído, variando entre os indivíduos, na medida das diferenças de suas experiências. 
Isso demonstra a importância em compreender o valor atribuído ao ambiente visando ações educativas e de conservação da biodiversidade (TONISSI, 2005, p.281). Por outro lado, a identificação dos problemas ambientais percebidos também se torna válida para adotar os recursos didáticos, as metodologias e as ações educativas cabíveis visando à transformação da realidade local.

Diante do exposto, o objetivo geral deste trabalho foi realizar um diagnóstico inicial sobre a percepção ambiental dos condutores do Parque Nacional do Itatiaia, a fim de reunir subsídios para futuras ações socioeducativas e, consequentemente, garantir uma experiência rica e agradável aos visitantes sem causar impactos significativos aos recursos socioeconômicos, culturais e naturais da área.

Neste sentido, os objetivos específicos foram: (1) conhecer o perfil dos condutores; (2) investigar as relações positivas - topofílicas e/ou negativas topofóbicas dos condutores com a paisagem percebida; (3) conhecer a percepção dos envolvidos sobre a relação ser humano-natureza-sociedade; (4) analisar a consciência e as atitudes ambientais dos investigados.

\section{Recorte espacial da investigação}

O estudo da percepção foi realizado com os condutores do Parque Nacional do Itatiaia com objetivo de conhecer o perfil e avaliar a qualidade da experiência vivenciada; investigando suas compreensões do processo de educação ambiental utilizando pelos condutores acerca do trabalho realizado no Parque Nacional do Itatiaia

O recorte escolhido conforme (Figura 1), foi o Parque Nacional do Itatiaia - parte baixa, onde os 15 entrevistados trabalham diretamente com o local.

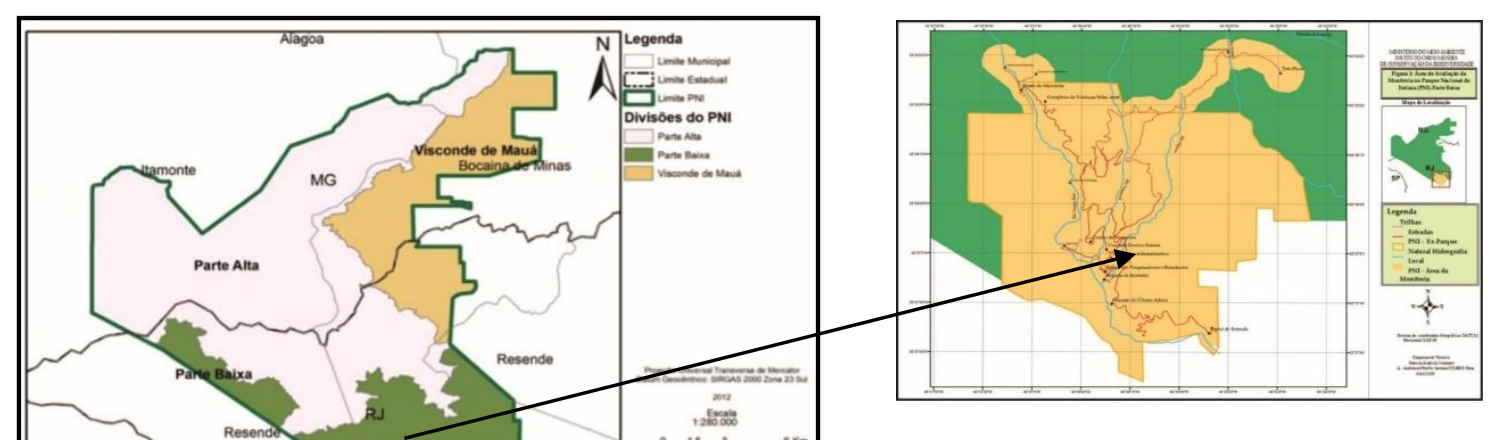

Figura 1 - Parque Nacional do Itatiaia e Recorte/Parte Baixa - Fonte: ICMBio 


\section{Material e métodos}

Pesquisas mostram que os indivíduos percebem e reagem diferentemente às ações sobre o ambiente em que vivem. As respostas são resultados das percepções (individuais e coletivas) dos processos cognitivos, julgamentos e expectativas de cada pessoa, influenciadas também por elementos culturais. Estes estudos são importantes para compreender as inter - relações entre homem e ambiente, suas expectativas, anseios, satisfações e insatisfações, julgamentos e condutas em relação ao espaço onde está inserido (VASCO; ZAKRZEVSKI, 2010, p.17-28).

Os indivíduos selecionados foram os condutores do PNI (Parque Nacional do Itatiaia); profissionais não credenciados pelo Instituto Brasileiro de Turismo (EMBRATUR), sem legislação específica no país para regulamentar a atuação destes profissionais; geralmente residentes do local ou próximo do local visitado e podem estar habilitados a acompanhar visitantes dentro de unidades de conservação.

Segundo o Ministério do Meio Ambiente (MMA/ Secretaria de Políticas para o Desenvolvimento Sustentável, 2005, p.53-54), ser condutor, não envolve apenas a habilidade de explicar sobre a área, mas também motivar o visitante a perceber e integrar-se ao local em que se encontra em seus mais diversos aspectos. Não basta somente acumular informações e transmiti-las, mas acima de tudo, saber quando e como transmiti-las. Sua função é estimular interesses, motivando o visitante a buscar mais conhecimento. Seu intuito deve ser mais amplo não se restringindo apenas à transmissão de informações, mas abrange a busca de crescimento pessoal na atividade, assim como tornar a experiência do visitante, a mais significativa possível.

Delimitada a área, partiu-se então para a aplicação de uma pesquisapiloto (teste), que serviu para constatar a necessidade de mais pesquisas relacionadas às percepções desses profissionais.

Essa pesquisa é classificada como descritiva, que consiste em descrever as características de determinada população e envolve o uso de técnicas padronizadas de coleta de dados: formulário e observação sistemática (GIL, 1991, p.115).

É também qualitativa, pois, de acordo com Minayo (1996, p.278), a investigação qualitativa requer a flexibilidade, a capacidade de observação e a interação com o objeto pesquisado. Para a coleta de dados, além de observação por parte do pesquisador, foram realizadas entrevistas semiestruturadas com os condutores do $\mathrm{PNI}$, e o uso de formulários que consistiu de coletânea de questões e anotações aplicadas, numa situação face a face que propiciou uma interação entre os entrevistados e o pesquisador.

Quanto aos meios, a pesquisa se apresenta como bibliográfica documental e de campo. A bibliográfica baseou-se em levantamentos e catalogação do referencial teórico-metodológico, mediante documentos pesquisados em sites da Internet, artigos de periódicos, dissertações, teses e livros, que serviram como base para subsidiar os instrumentos analíticos Revbea, São Paulo, V. 12, № 2: 229-250, 2017. 
relativos às variáveis de estudo. $E$ de campo, com a finalidade de obter repostas para atingir o objetivo proposto (VERGARA, 2010, p.148).

$O$ instrumento de pesquisa utilizado foi um formulário, havendo a participação simultânea do pesquisador na hora em que as entrevistas foram efetivadas, sendo dividido nas seguintes áreas: Identificação do entrevistado; níveis de conscientização ambiental; grau de importância de problemas ambientais inerentes ao local de estudo e educação ambiental.

No que se refere à técnica empregada neste trabalho, constatou-se, através da literatura consultada, que a grande maioria dos trabalhos envolvendo a percepção do meio ambiente e a percepção em Geografia está de alguma forma vinculada às obras de Whyte (1977) e Zube (1982, p.1-33), pois mesmo quando adaptadas preservam, na sua essência, os fundamentos principais destes autores. Neste trabalho, a metodologia adotada foi à proposta por Whyte $(1977$, p.80) e igualmente utilizada por Sartori $(2000$, p.96), que sugeriu adotar um triângulo metodológico de pesquisa formado pela tríade observando, perguntando/ouvindo e registrando.

\section{Observação in loco}

A coleta dos dados foi realizada pelo próprio pesquisador durante os meses de agosto a outubro de 2016 e efetuada em diferentes horários do dia, tendo como locais de coleta os encontros realizados com os condutores no PNI. Antes da aplicação do instrumento de pesquisa, o entrevistado foi informado dos objetivos da investigação e salientada a importância de se ter uma informação precisa.

Em relação ao tamanho da amostra utilizada (no. de entrevistados) não se encontrou na bibliografia consultada um número consenso que pudesse ser considerado como o mais indicado, pois varia de acordo com as necessidades, objetivos e locais de cada trabalho. Neste sentido, (MACHADO, 1988: p.112) destaca:

A medição na abordagem perceptiva é uma tarefa difícil e delicada, em face da riqueza e complexidade dos significados dos objetos da percepção humana. Onde o medir envolve diretamente a escolha dos procedimentos e técnicas de campo a serem utilizados na obtenção de respostas, capazes de permitir que se entenda como acontece a percepção do meio ambiente pelos homens.

A partir deste entendimento foi fixado um total de 15 entrevistados, de 30 cadastrados, número considerado suficiente para que os objetivos propostos fossem alcançados a contento, além de permitir a coleta das informações via instrumento de medida elaborado. A seleção dos mesmos seguiu alguns critérios, tais como: que fossem pessoas de ambos os sexos e estivessem registrados como condutores no PNI.

Quanto à abordagem da pesquisa, foi apresentado aos condutores um questionário contendo oito questões, onde se buscou observá-los em sua área 
de trabalho, registrando, analisando, classificando e interpretando de forma que não houvesse nenhuma interferência do pesquisador.

A coleta de dados se deu com entrevistas pessoais e observação in loco do trabalho desenvolvido por cada condutor.

Foram analisados alguns aspectos do perfil sociocultural dos profissionais. A análise de educação ambiental e a percepção dos impactos ambientais foram adaptados dos roteiros de classificação de Sauvé et al. (2000 apud FIORI, 2002, p.95).

Além disso, também foi analisada a percepção dos profissionais quanto aos sentimentos topofílicos e topofóbicos representados pela paisagem do PNI.

Foi apresentado um conjunto de fotos, divididas em dois blocos temáticos, com legendas apenas nos nomes dos atrativos para que deixasse 0 respondente livre em suas análises sobre cada foto. Os blocos temáticos foram assim divididos: 1 - Representação da paisagem do PNI e 2 - Percepções sobre impactos ambientais.

Coletado os dados, todas as informações obtidas foram tabuladas mediante respostas semelhantes, quantificadas, analisadas e interpretadas em seu significado. Para identificar as paisagens que mais despertaram sentimentos topofílicos e topofóbicos nos condutores considerou-se apenas as paisagens citadas por, no mínimo, cinco pessoas. Esta decisão foi justificada pelo fato de que não se pretende buscar a ideia individual que cada indivíduo tem da paisagem do PNI, mas sim, a imagem coletiva que um determinado grupo de pessoas tem do cenário em estudo.

Além dos métodos descritos anteriormente, foram realizados, em todas as etapas, registros fotográficos que auxiliaram na análise dos mapas comportamentais.

Para que não houvesse comprometimentos e para não deixarem as pessoas desconfortáveis, as fotos foram tiradas de maneira que os condutores não pudessem ser identificados. Para enriquecimento do trabalho, também foram feitos registros orais, durante conversas informais com os envolvidos a respeito do ambiente.

\section{Discussão e análise dos resultados}

A Portaria № 204, de 10 de julho de 2013 (ICMBio), prevê que todos os condutores devam residir nos municípios pertencentes aos estados que estão inclusos nos limites do Parque, quais sejam: Itatiaia/RJ, Resende/RJ, Itamonte/MG, Itanhandu/MG, Passa Quatro/MG, Alagoa/MG, Bocaina de Minas/MG e Queluz/SP. Dos 15 condutores entrevistados, 47\% residem nos municípios de Minas, 33\% no município de Itatiaia, 20\% no município de Resende e nenhum registro no município de São Paulo.

Possuem variação média de idade entre 25 a 70 anos, $70 \%$ são homens e $30 \%$ mulheres, destacando que $67 \%$ dos condutores são Revbea, São Paulo, V. 12, № 2: 229-250, 2017. 
masculinos, fato que se dá pela grande maioria serem mais jovens e possuírem maior vigor físico, podendo assim realizar as atividades longas, como as travessias e escaladas, e de serem conhecidos na região onde atuam com "mateiros" e terem o total conhecimento das trilhas, por conta de residirem, desde o nascimento, no lugar.

Os $3 \%$ dos condutores masculinos não realizam trilhas de longa duração, por conta da idade avançada, só fazem atividades na parte baixa onde o acesso é mais fácil.

Em relação ao corpo feminino de condutores, apenas $17 \%$ não atuam em atividades de longa duração, fato esse, que demonstra a pouca disposição, por conta da idade e do contexto social (por haver pernoites de até três dias no meio da floresta e permanecerem isoladas e sem a nenhum tipo de comunicação). Vale um destaque quanto ao corpo masculino ser maior na profissão, pois o ato de conduzir na região vem dos tropeiros que iniciam seus filhos na profissão desde os 10 anos de idade, na venda de queijos entre Minas e Rio, trecho esse utilizado pelos condutores em suas travessias em épocas de grande temporada (abril a outubro/época de estiagem na região) tanto de escaladas, quanto de travessias para aumentar a renda familiar.

Em relação ao nível de escolaridade, dos 15 condutores entrevistados, $64 \%$ possuem Ensino Médio e $36 \%$ nível superior. Vale destacar que para ser condutor do Parna (Parque Nacional) a condição mínima escolar exigida é ter o nível médio completo. Dos 15 entrevistados, os $36 \%$ frequentam ou já concluíram cursos acadêmicos / técnicos na área ambiental.

Quanto à profissão exercida pelos entrevistados, $73 \%$ possuem outra ocupação utilizando a profissão de condutor como segunda renda; os $27 \%$ restantes vivem exclusivamente dessa renda. A pesquisa aponta um número diversificado de funções entre elas à de maior expressão é a de estudante, seguida pelos comerciários, técnicos em enfermagem, serviços gerais, professores, aposentados e militares.

Faz necessário ressaltar os militares aposentados que compõem o quadro de condutores do Parque, destacando a cidade de Resende como um importante centro militar, fruto de sua função histórica, o que eleva o número de militares que moram na cidade, sem contar que a grande maioria de seus treinamentos táticos era, e ainda são, realizados dentro do Parna, tanto na Parte baixa, quanto na Parte alta.

Entrevistados sobre qual seria a função de um parque, $60 \%$ responderam como função principal a Ecológica; $13 \%$ como sendo Educativo e Ecológico; $20 \%$ como Religioso e 7\% Todas.

Os resultados referem-se à importância das pesquisas realizadas no Parque por diversas instituições de ensino e dos cursos oferecidos, como o Curso de Multiplicadores sendo aspectos positivos e sensibilizadores dos visitantes, da comunidade, incluindo os próprios entrevistados. 
Foi percebido que o Curso de Multiplicadores tem sido uma das bases principais de capacitação e fomento para as práticas de Educação Ambiental, fortalecendo, assim, o conhecimento do cenário local através de debates sobre temas importantes para a operacionalização de ações educativas no Parna e seu entorno.

Dos 15 entrevistados sobre como concebia o PNI antes de se tornar condutor, $80 \%$ dos entrevistados responderam como Unidade de Conservação, 13\% como Santuário e 7\% como Ambiente Frágil.

O resultado obtido nessa questão diz respeito ao fato de todos os entrevistados estarem inseridos, de alguma forma, nos programas de capacitação e voluntariado oferecidos pelo Parque. Vale destacar que como critério para atuar como condutor após aprovação nas provas, o mesmo deve trabalhar de forma voluntária por, no mínimo, três visitações para adquirir experiência e vivência com os visitantes, mediante acompanhamento de outros condutores mais experientes.

Dos 15 condutores questionados de qual forma trabalhava a Educação Ambiental, somente $7 \%$ usam de dinâmicas e processos lúdicos como meio de sensibilização. Um percentual de $93 \%$ não trabalha utilizando tais métodos, apenas focam na parte histórica e de lazer.

Foi constatado que existem dificuldades para a incorporação do lúdico e de dinâmicas nas conduções realizadas pelos profissionais, indicando a necessidade de maior capacitação profissional utilizando essa ferramenta como veículo de aprendizagem.

Segundo Barcelos (2008, p.53), novas alternativas metodológicas na educação em geral e na educação ambiental em particular, precisam de um envolvimento afetivo, lúdico, amoroso, de todos aqueles e aquelas que se dedicam, sob pena de a transformarmos em mais uma mera tarefa a ser cumprida. Barcelos cita ainda que o grande desafio dos educadores e pesquisadores em Educação Ambiental é criar uma forma onde a temática ambiental esteja presente em todas as disciplinas ou no maior número possível delas. Então, percebe-se a necessidade de buscar alternativas para o trabalho com a educação ambiental e a validade do trabalho lúdico multidisciplinar, uma vez que o aprendizado se dá por intermédio de atividades que envolvem a descontração, ao mesmo tempo em que integra conhecimentos e habilidades.

Edgar Dale, autor do "Cone das Experiências" (Figura 2), citado por Telles (2002, p.31), enfatiza que o ensino puramente teórico (simbólicoabstrato) deve ser evitado. O que é imediatamente vivenciado permite uma aprendizagem mais efetiva. 


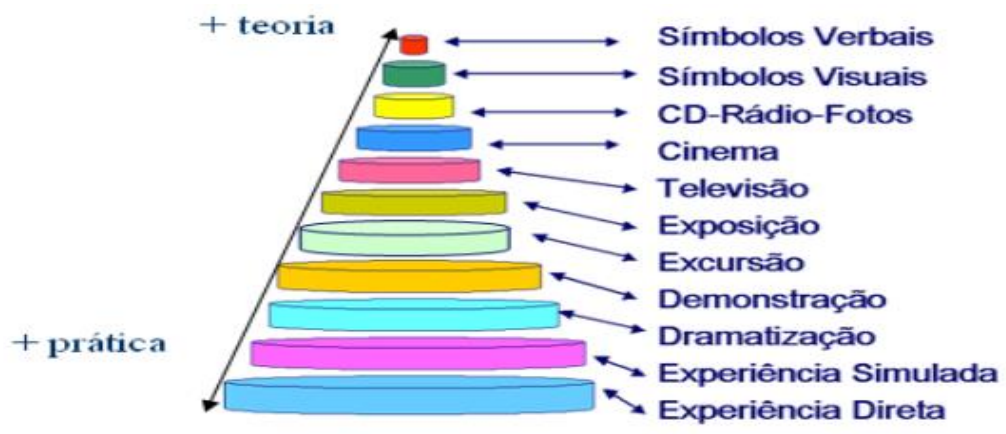

Figura 2: O Cone das Experiências. Fonte: Adaptado de Pilleti (1991)

A base do cone representa as experiências diretas com a realidade e as instâncias seguintes indicam, cada vez mais, maior grau de abstração, na medida em que se aproximam do vértice do cone. O processo de aprendizagem é tanto mais eficaz quanto mais se possa realizar uma experiência direta.

Sendo assim, as atividades lúdicas, podem colocar o indivíduo em diversas situações, onde ele pesquisa e experimenta, fazendo com que ele conheça suas habilidades e limitações, que exercite o diálogo, a liderança seja solicitada ao exercício de valores éticos e muitos outros desafios que permitirão vivências capazes de construir conhecimentos e atitudes (DOHME, 2008, p.55).

Segundo os behavioristas a aprendizagem é uma aquisição de comportamentos através de relações mais ou menos mecânicas entre um estímulo e uma resposta.

Numa abordagem cognitiva, considera-se que o homem não pode ser considerado um ser passivo. Ele organiza suas experiências e procura Ihes dar significado. Enfatiza a importância das funções mentais do processo de aprendizagem, na forma como se percebe, seleciona, organiza e atribui significados aos objetos e acontecimentos. Numa abordagem social, as pessoas aprendem observando outras pessoas no interior do contexto social.

Portanto, a aprendizagem tem um sentido amplo: abrange os hábitos em que formamos os aspectos de nossa vida afetiva e a assimilação de valores culturais. Enfim, aprendizagem refere-se a aspectos funcionais e resulta de toda estimulação ambiental recebida pelo individuo no decorrer da vida.

Segundo Campos (2006, p.69-94) a ludicidade, nas suas diversas formas, auxilia no processo ensino-aprendizagem, tanto no desenvolvimento psicomotor, bem como no desenvolvimento de habilidades do pensamento, como a imaginação, a interpretação, a tomada de decisão, a criatividade, o levantamento de hipóteses, a obtenção e organização de dados e a aplicação dos fatos e dos princípios a novas situações que, por sua vez, acontecem 
quando jogamos, quando obedecemos a regras ou quando vivenciamos conflitos.

A questão "o que você entende como percepção ambiental", faz uma análise dos saberes apresentados de cada condutor entrevistado. Cada condutor foi numerado de um a quinze, facilitando assim a análise de cada resposta dada.

O conceito de percepção ambiental foi controverso, pois a grande maioria dos condutores apresentou respostas variadas à questão. Dos 15 entrevistados, $20 \%$ escreveram que a percepção ambiental está intimamente ligada às questões afetivas e a forma de como sensibilizar o visitante, mas não explicaram como fazem para que isso aconteça.

Um total de $60 \%$ relacionou a percepção ambiental á educação ambiental, 7 \% não responderam à questão e 13\% apresentaram variadas respostas.

O questionário aplicado sobre a percepção ambiental com os condutores do PNI proporcionou dados e registros sobre suas percepções subjetivas a respeito do meio ambiente e dos problemas. Tal pesquisa teve 0 escopo de identificar os aspectos que fragilizam ou potencializam o nível de satisfação do trabalho exercido. Através das respostas dadas, foi possível verificar o nível de entendimento dos condutores e os seus sentimentos referentes à paisagem. Assim, a proposta de ações motivacionais para o aprendizado e a promoção da qualidade ambiental pode ser sustentada pelo conhecimento concreto das expectativas dos atores envolvidos e de suas experiências concretas.

Todos os estudiosos da percepção ambiental concordam que a análise do espaço geográfico implica diretamente no olhar acerca do ambiente. Segundo Tuan (1983, p.184), existe uma estreita relação entre vivência e tempo. Para ele, não é possível adquirir senso de lugar pelo simples ato de cruzar por ele. Assim, particularidades como, o tempo e a localização da área onde se reside, influem na interpretação e na valoração que damos aos mais variados ambientes.

O que se pretendeu avaliar não foi a quantidade de conhecimento sobre o meio ambiente, mas a capacidade destes em acioná-los e buscar novos saberes para realizar, na prática, atitudes e comportamentos ambientalmente positivos. Portanto, os instrumentos de avaliação só cumprem com sua finalidade se puderem diagnosticar o uso funcional e contextualizado dos conhecimentos ambientais.

Para medir o grau de importância aos problemas ambientais enfrentados pela Unidade de Conservação, foi solicitado aos entrevistados que manifestassem sua opinião em relação aos problemas apresentados. Para tal, utilizou-se uma escala de importância de problemas de cinco posições, onde 1 representa " pouca importância à afirmação" e 5 " muita importância à afirmação". 


\section{Questões apresentadas}

- Importância que os alunos do entorno dão ao Parque;

- Importância que os Professores dão ao Parque;

- Importância que os servidores dão aos programas de Educação Ambiental oferecidos pela Câmara Técnica de Meio Ambiente;

- Importância ao debate construtivo entre os condutores, inerente às problemáticas do Parque, como: vandalismo, pichações e alimentação inadequada aos animais silvestres;

- Importância de ações de prevenção de problemas ambientais na comunidade do entorno, como exemplo, as queimadas;

- A importância que os moradores do Parque dão para as ações de separação dos resíduos.

Referente às respostas dadas a importância que os alunos do entorno dão ao Parque, $87 \%$ dos 15 condutores entrevistados, concordaram que os alunos, dão muita importância e que quando visitam o Parque vivenciam e experimentam todos os conhecimentos dados em sala de aula, porém, percebe-se a dificuldade da maioria das escolas em levar seus alunos ao Parque, por conta da escassez de transporte na região.

O ensino, de uma forma geral, pode se processar em diferentes contextos educacionais e espaciais. Para cada contexto, diferentes definições e caracterizações devem ser levadas em conta como faixa etária e seguimento educacional.

Segundo Rangel (2005, p.140) o processo de ensino-aprendizagem pode ter sua eficácia melhorada quando o conhecimento trabalhado se torna mais facilmente assimilável pelo aluno. Esta assimilação é facilitada, em maior ou menor grau, de acordo com os métodos e técnicas empregados.

O uso de ambientes não formais possibilita a contextualização, aplicação e associação de conceitos e conhecimentos já aprendidos com as informações novas, do ambiente, reduzindo as exigências de abstração do aprendiz e permitindo uma compreensão mais eficiente dos conhecimentos.

Novas ideias e informações podem ser aprendidas e retidas, na medida em que conceitos relevantes e inclusivos estejam adequadamente claros e disponíveis na estrutura cognitiva do indivíduo. O desenvolvimento de aulas em espaços não formais pode possibilitar a integração de informações oriundas da intervenção e interpretação do ambiente para a associação com os conceitos já interiorizados na estrutura cognitiva do aprendiz.

Sobre este aspecto cognitivo, vale ressaltar que as práticas desenvolvidas fora de sala de aula devem estar em consonância com os objetivos curriculares, possibilitando assim a percepção de um sentido maior ao que é aprendido pelos estudantes. 
Sobre este assunto, Lowman (2004, p.223) considera que as tarefas de observação e as experiências praticadas podem enriquecer a interação dos alunos com os conteúdos apresentados em sala de aula, ajudando-os a ver a relevância das interações com as questões da vida real e das experiências humanas. Porém, se faz necessário que esses mesmos alunos sejam encorajados a analisar, sintetizar e a avaliar os conceitos aos quais foram apresentados.

As atividades de observação e de experiência práticas terão mais valor educacional se forem planejadas para serem integradas com os objetivos previamente elencados com a visitação. Quando estas atividades bem programadas e bem desenvolvidas, podem ser igualadas com o "tempero faltante em nossa comida". (Condutor $\mathrm{n}^{\circ}{ }^{5}$ )

Referente às respostas dadas a importância que os professores dão ao Parque, $67 \%$ afirmaram que os professores dão pouco ou quase nenhuma importância ao PNI. Infelizmente, a grande maioria, se encaixa em baixos salários, o que desmotiva o planejamento e a preparação de atividades, e incorporado a essas questões, adiciona-se a falta de transporte e as poucas e ineficientes fomentações da secretaria de Educação em desenvolver projetos integradores entre as escolas e o Parque.

Vale destacar a iniciativa realizada pela Associação Educacional Dom Bosco, juntamente com o PNI, em realizar um projeto integrador denominado PNIVE (Parque Nacional do Itatiaia vai à Escola), a respeito da necessidade de transformar visitas formais de escolas públicas e particulares em visitas orientadas para um novo olhar, que envolva não a contemplação estática de uma unidade de conservação da natureza, mas uma educação ambiental que ultrapasse o conservacionismo e vá além, proporcionando mudança de mentalidade em relação à qualidade de vida, diretamente ligada ao tipo de convivência que se mantém com a natureza e que implica em novas atitudes, valores e ações.

O caminho encontrado para essa abordagem foi invertido: o Parque é que vai à escola. Aceitando o desafio, a AEDB prepara alunos graduandos, voluntários, independentemente de sua área de formação, através de curso de Iniciação à Docência em Educação Ambiental, tendo como foco o Parque Nacional do Itatiaia para, em seguida, através de convênio, levar o conhecimento às Escolas e acompanhá-las em visitas orientadas ao Parque.

Analisando as respostas referentes à importância que os servidores dão aos programas de Educação Ambiental oferecidos pela Câmara Técnica de Educação Ambiental foi percebido, que, quase a totalidade dos 15 condutores entrevistados (93\%) percebe que os servidores não possuem qualquer tipo de envolvimento com os programas e atividades ofertadas pela CTEA.

Foi observado que a falta de interesse e envolvimento sobre as questões inerentes ao Parque deve se dar, por conta de que quase metade dos servidores, estarem em processo de aposentadoria e a outra parte são 
servidores terceirizados. Estes últimos, por conta de salários atrasados, não se sentem motivados a participar das reuniões oferecidas pela CTEA.

Outro aspecto abordado pelos condutores foi a falta de comunicação entre os assuntos discutidos (Câmaras e o próprio Conselho Consultivo) nas reuniões frente aos interesses dos servidores, o que facilitaria a comunicação, a integração e as ações dentro do Parque.

Referente à questão apresentada - "Sobre a importância de ações de prevenção de problemas ambientais na comunidade do entorno", como exemplo as queimadas, dos 15 entrevistados, 100\% acham de suma importância ser desenvolvido para os moradores da Parte Alta e comunidade do entorno, palestras informativas sobre a utilização das queimadas controladas, assim, evitaria os incêndios provocados pela ação do homem. É notório na região, que as queimadas costumam acontecer com mais frequência no mês de agosto, apresentando condições de seca extremamente crítica, seria viável então, como sugestão dos condutores, iniciarem as palestras no início de julho.

Quanto à importância que os moradores do Parque dão para as ações de separação dos resíduos, 100\% concordaram com o trabalho desenvolvido pelos moradores do Parque em relação ao lixo. Destaque para a moradora do Parna, Tatiana Clauzet que através da AAl (Associação de Amigos do Itatiaia) desenvolve ações de Educação Ambiental, panfletagem e conversas informais com cada morador do PNI/Parte baixa. Presença constante nas reuniões da Câmara Técnica de Meio Ambiente, teve papel importante nas construções das casinhas de lixo anexadas ao longo do Parque, evitando as ações dos macacos pregos.

Outro Projeto que vale destaque é o Projeto Primatas do Itatiaia, organizado pelo professor e Coordenador Sócio Ambiental do PNI, Luiz Sérgio Sarahyba, que através de ações ambientais, desenvolve atividades para evitar que os turistas alimentem indevidamente os macacos, que no período de maior visitação (feriados/férias) se mostram muito mais constantes nos atrativos.

Referente às respostas dadas à importância do debate construtivo entre os condutores inerentes as problemáticas do Parque, como vandalismo, pichações e alimentação inadequada aos animais silvestres, dos 15 entrevistados, todos concordaram da necessidade de haver uma maior inclusão juntamente com projetos integradores, onde através das ações em conjunto buscariam melhores soluções, mais participativas de forma que envolvessem todos os condutores, principalmente os que residem nos municípios de Minas Gerais, que por conta da distância, acabam ficando excluídos das iniciativas. Vale ressaltar que os debates acabam levando o indivíduo a construir uma sociedade mais sustentável, socialmente justa e ecologicamente equilibrada.

A principal função do debate construtivo é contribuir para a formação de condutores conscientes, aptos a decidir e atuar na realidade socioambiental de um modo comprometido com a vida, com o bem - estar de cada um e da 
sociedade, local e global. Para isso é necessário que, mais do que informações e conceitos, o PNI se proponha a trabalhar com atitudes, com formação de valores, com o ensino e aprendizagem de procedimentos. E esse é um grande desafio a ser construído.

Foi apresentada aos condutores uma imagem, do fotógrafo Ricardo Deutsch Junior, onde se buscou a sensibilização pela imagem.

Dos 15 indivíduos amostrados, 93\% alegam que a imagem os sensibilizou, sendo elencadas as seguintes categorias de indivíduos:

Cat. 1- Visão diferente;

Cat. 2- Visão do espaço físico;

Cat. 3- Percepção à presença de vegetação;

Cat. 4- Percepção à imagem;
Cat. 5- Mais de uma categoria;

Cat. 6- Parque possui um imenso potencial educador;

Cat. 7- Respostas desconexas, ambíguas ou sem justificativa

Houve o predomínio da Cat. 2, com $34 \%$, de indivíduos que se reportam à visão do espaço físico, enquanto que $27 \%$ se enquadram na Cat. 5 (respostas que se enquadram em mais de uma categoria). Já com $20 \%$, ocorre a Cat. 1 (permitem uma visão diferente), e a Cat. 6,13\% de indivíduos que acreditam que o parque possui um enorme potencial educador. Em quinto lugar no ranking de categorias, situa-se a Cat. 4, em que $7 \%$ dos indivíduos salientam a sensibilização gerada pela própria imagem.

É oportuno destacar que ao se mencionar o processo fundiário existente no Parque, deve-se considerar que, mesmo não estando relacionado às categorias, nem a imagem apresentada, quase que $90 \%$, se mostraram incomodados por tal processo, ressaltando a forma como vem sendo conduzida pela gestão do Parque.

Santos (2007, p. 96) ressalta a contribuição do uso das imagens de satélite para os estudos ambientais, revelando a dinâmica do processo de construção do espaço geográfico. Além disso, Florenzano e Santos (2003, p. 775-780) destacam que as imagens de satélite são cada vez mais frequentes nos meios de comunicação visual, em livros e atlas. Contudo, até então foram pouco exploradas como potencial uso na Educação Ambiental.

No que diz respeito à análise do lugar através da imagem, observouse, que, no Parque, 67\% dos Condutores consideram que a imagem gerou sensibilização, enquanto que os 33\% dos entrevistados não se sensibilizaram.

Mais do que as palavras, as imagens produzem sentimentos, identificação, favorecem lembranças, disparam a imaginação, a introspecção, entendimentos, anunciam ou denunciam uma realidade, evocam memórias pessoais e visões de mundo. O olhar chega antes da palavra, ou seja, os seres 
humanos, antes de aprender a falar, comunicam-se pela visão. Assim, olhar é um ato de escolha.

A percepção de qualquer imagem é afetada pelo que sabemos ou pelo que acreditamos. Com isso, pode-se entender que toda imagem incorpora uma forma de ver.

$\mathrm{Na}$ imagem estão implícitos signos e significados, já que, de acordo com o campo da semiologia, devemos considerar que a uma palavra ou seu significado, está associada uma representação, uma imagem mental. Mesmo que consideremos as diferenças culturais como distinções para reconhecimento de significados ou reconhecimento/representação de uma palavra, podemos dizer que há na imagem um caráter mais abrangente de entendimento e significação.

Vivemos em um mundo hiper-visual, onde a imagem exerce um papel fundamental de identificação, divulgação ideológica e socialização de significados. Nesse sentido, é fundamental que as ciências humanas e sociais reconheçam o potencial das imagens com fins de investigação social, mesmo que a criação delas possa ser caracterizada como uma atividade que exige especialização.

Assim, devemos considerar que a imagem não representa a realidade plasmada em uma superfície amorfa, mas que é constituída e produzida pela realidade social, que é mediadora entre o sujeito que a produz e aquele a quem se destina; logo, neste texto a imagem é considerada como um artefato cultural, ainda que não seja o real, apresenta, representa ou reapresenta $o$ mundo, tornando presente aquilo que está ausente.

A imagem, especialmente a fotografia, tem o poder de trazer de volta 0 ausente, o distante, de materializar aos olhos o que não está materialmente ao alcance das mãos. Podemos dizer também que a imagem produz sentidos, pois, "não há SE ou TALVEZ na imagem. A imagem É" (NOVAES, 2008, p.5253).

Quanto aos 33\% que não se sensibilizaram com a imagem, também foram elencadas oito categorias:

Cat. 1- Percepção ao espaço físico;

Cat. 2- Imagem não mostra a realidade;

Cat. 3- Somente uma imagem real;

Cat. 4- Relação à qualidade da tecnologia da imagem;
Cat. 5- Mais de uma categoria;

Cat. 6- Percepção à vegetação;

Cat. 7- Sem justificativa;

Cat. 8- Sensibilização se deu pela visão da imagem. 
Com $50 \%$, predominou a Cat. 7 - Sem justificativa, ou seja, estes indivíduos, embora julguem que a imagem não os sensibilizou, não expuseram suas justificativas. Com 33\%, predomina a Cat. 3 (acreditam ser somente uma imagem real), seguida pela Cat. $2 \mathrm{com} \mathrm{17 \%} \mathrm{(acreditam} \mathrm{que} \mathrm{a} \mathrm{imagem} \mathrm{não}$ mostra a realidade). Assim, percebe-se o modo diferenciado de reação à imagem por parte dos Condutores, especialmente no que diz respeito à visão do real e do imaginário.

Quando questionados sobre o que acham que poderia ser feito para melhorar esses níveis de percepção ambiental e de que forma, também responderam de maneira diferente. Para suas respostas, foram elencadas cinco categorias:

Cat. 1- Projeto integrador com o Parque/ entre cursos oferecidos;

Cat. 2- Campanhas de conscientização e preservação;

Cat. 3- Sugestão do desenvolvimento de ações, como: melhores transportes voltados para os turistas, programas pedagógicos direcionados a cada série e acessibilidade;

Cat. 4- Mais de uma categoria;

Cat. 5- Introdução de cursos de aperfeiçoamento sobre as questões relativas ao Parque de uma maneira geral, onde ofereceriam mais subsídios para trabalharem com os visitantes.

Dos 15 condutores entrevistados, predominou a Cat. 1 (37\%), que sugerem a realização de projetos integradores com o Parque/ entre cursos oferecidos, seguida pela Cat. $2(25 \%)$ que sugerem a realização de campanhas de conscientização e preservação.

Cabe destacar o percentual da Cat. 3 (19\%), onde os entrevistados sugerem o desenvolvimento de ações, como: melhores transportes voltados para os turistas, programas pedagógicos direcionados a cada série e acessibilidade. Por fim, a Cat. 4 onde $13 \%$ responderam a mais de uma resposta e com $6 \%$ a Cat. 5 com a introdução de cursos de aperfeiçoamento sobre as questões relativas ao Parque.

\section{Conclusões e Considerações Finais}

O meio ambiente é percebido pelos indivíduos de forma múltipla e diferenciado, uma vez que a compreensão se dá sob uma perspectiva subjetiva, apoiada numa realidade concreta. Isto porque a percepção ambiental é condicionada por fatores inerentes ao próprio indivíduo; fatores educacionais e culturais imprimidos pela sociedade, que condicionam sua sensibilidade e atitude e fatores emotivos, afetivos e sensitivos, derivados das relações obtidas com o ambiente (FERREIRA; COUTINHO, 2000, p.171-188).

Revbea, São Paulo, V. 12, № 2: 229-250, 2017. 
Cada indivíduo enxerga e interpreta o meio ambiente de acordo com o seu próprio olhar, suas experiências prévias, expectativas e ansiedades. Ao considerar os níveis de percepção ambiental verifica-se que os grupos humanos possuem bagagens experienciais distintas devido a elementos como cultura, faixa etária, gênero, nível socioeconômico, entre outros, que revelam percepções sob diversas formas. Pode-se afirmar, portanto, que a discussão sobre as questões ambientais reflete interesses e visões de mundo diferenciado, além de conflitos entre valores, atitudes e percepções.

Muitos estudos ambientais restringem-se a uma visão de que através da adoção da legislação, fiscalização e de tecnologias os problemas relacionados ao meio ambiente serão solucionados. No entanto, se estas medidas não forem associadas a uma compreensão das experiências, sentimentos e expectativas de todos os atores sociais envolvidos, as ações tornam-se incipientes, parciais e de curto prazo. Portanto, devem-se respeitar as experiências e vivências que as pessoas possuem com os lugares em que constroem seu cotidiano, afinidades, memórias, identidades (FADINI, 2005, p.112).

A pesquisa investigou como a paisagem do PNI é percebida e experienciada por seus condutores, mediante um estudo topofílico e topofóbico da paisagem vivenciada.

A investigação teve como base de análise e estudo o conhecimento do próprio condutor, advindo de sua cotidianidade, experiência e vivência no Parna. Ressalta-se que a análise da vivência dos condutores permitiu descortinar e decodificar elementos importantes da paisagem percebida, bem como conhecer elementos físicos e humanos que a compõem. Entre estes elementos os de maior expressão foram os signos, marcas que foram impressas pela sociedade ou pela natureza no espaço vivido do mesmo, e que ao serem analisados permitiu desvendar os afetos e desafetos daqueles que 0 experienciam.

Ao se conceber a paisagem do PNI como um fenômeno vivido, deparase com um mundo de significados, experiências e aspirações daqueles que foram abordados pela pesquisa, e a partir de suas percepções teceram-se as considerações presentes neste trabalho.

Com o desenvolvimento da pesquisa, verificou-se que entre as paisagens mais preferidas estão as Cachoeiras do Poranga, Véu de Noiva, Pico das Agulhas Negras, e as Prateleiras, figurando entre as mais belas paisagens. Entre as preteridas, as de maior significado são as paisagens relacionadas aos acessos do $\mathrm{PNI}$, que de acordo com a percepção dos entrevistados, são as mais desinteressantes do lugar.

Durante a análise topofílica e topofóbica, pode-se constatar que as paisagens do PNI estão tanto entre as suas mais agradáveis, quanto entre as menos agradáveis. Esta ambiguidade fora justificada pelos argumentos apresentados, onde todos, sem exceção, mencionaram elementos estruturais de uma paisagem interferida pela quantidade de pessoas em grandes períodos

revista brasileira educação ambiental 
de visita e a uma gestão intolerável, paralelamente ao destaque às belezas naturais do PNI.

Neste sentido, há que se destacar a relevância social deste trabalho, pois os resultados aqui apresentados permitem inferir soluções plausíveis à rejeição e ao desagrado de parte dos condutores para com a infraestrutura do PNI e sua respectiva manutenção. A ambiguidade de sentimentos topofílicos e topofóbicos apresentados pode ser facilmente resolvida mediante a elaboração de uma política séria de planejamento, gerenciamento e manutenção de algumas áreas citadas como abandonadas. Acredita-se que tais políticas ao serem colocadas em prática minimizariam os problemas estruturais da paisagem.

Portanto, se os problemas estruturais mencionados fossem resolvidos ou ao menos minimizados, a satisfação dos condutores atingiria os níveis desejáveis.

No caso dos elementos aversivos, destacaram-se: a falta de sinalização nas trilhas, a falta de material educacional para ser entregue aos visitantes, e a falta de cuidado e de manutenção com alguns espaços que se encontram abandonados, todos inclusos no conceito das paisagens topofóbicas evocadas pela pesquisa.

No que se refere aos aspectos humanos, ressalta-se que a falta de formação adequada e periódica dos funcionários é, de acordo com a grande maioria dos entrevistados, fator determinante da inadaptação e ineficácia de muitos serviços. Embora estes problemas sejam comuns na maioria dos cenários das Unidades de Conservação do Brasil e do mundo, eles podem ser minimizados através de uma política de inclusão social e participativa feita em conjunto pelos três níveis de administração pública do país.

Os resultados da pesquisa permitiram também conhecer e reconhecer o espaço e com isto, detectar algumas de suas principais carências, como a falta de funcionários, falta de espaços destinados para o lixo, carência de políticas educacionais referentes á não alimentação de animais exóticos e à retirada de vegetação, destacando ainda a grande necessidade de programas de educação ambiental para os visitantes em dias não recomendáveis para trilhas.

Salienta-se ainda que o conhecimento do PNI através de sua paisagem vivida apresentou um rol de significações e aspirações, pois como coloca Tuan (1980, p. 215), o conhecimento de um lugar varia muito de indivíduo para indivíduo, pois depende, antes de tudo, do que as pessoas vão nele procurar: alimentação, moradia, saúde, educação, trabalho ou lazer.

Apesar disso, cada entrevistado demonstrou ter uma imagem mais forte, mais marcante, que mesmo filtrada por percepções individuais e valores culturais diferentes, culminou em um retrato fiel do PNI. Este retrato é, segundo os resultados da pesquisa, representado pela paisagem das Agulhas Negas, espontaneamente aclamada como a imagem-símbolo do Parque, pois identifica claramente as atividades de montanhismo, sua vegetação e fauna endêmica. $O$ Revbea, São Paulo, V. 12, № 2: 229-250, 2017. 
cenário mencionado expressa o pulsar do lugar, ou seja, quase todas as atividades turísticas, voltadas para o montanhismo são realizadas na Parte Alta, onde o Pico das Agulhas Negras está situado.

É no Centro de Visitantes ( $\mathrm{CV}$, como é conhecido pelos condutores) que ocorre grande parte dos encontros e reencontros entre amigos, alguns de longa data, mas que por razões diversas não se veem há algum tempo, mas que acabam ali se reencontrando. Além disso, se apresenta como cenário onde permeia a difusão de ideais ambientais, políticas, econômicas, culturais e ideológicas.

Entretanto, há de se destacar que as paisagens não são estáticas, mas sim, transformadas quase que diariamente a fim de atender as novas exigências dos visitantes. Desta forma, tanto o espaço geográfico como as suas categorias de análise são modificadas com o passar do tempo. Assim, as paisagens topofílicas de hoje, podem não ser as mesmas de amanhã, assim como aquelas que são preteridas hoje podem se tornar agradáveis futuramente.

A este respeito, deve-se destacar a crescente tomada de consciência, por parte de profissionais envolvidos, com a questão ambiental e ao planejamento. Sobre este aspecto, Amorim Filho (1992, p. 16-20) diz que no mundo inteiro, até mesmo no Brasil, apesar de incipiente, multiplicam-se as ações de resgate, reabilitação ou restauração de lugares, paisagens e conjuntos ambientais.

Contudo, acredita-se que estas nuanças, também sejam reflexos da dinamicidade da vida, do espaço socialmente construído que, de tempos em tempos, é ampliado, reestruturado pela ação de atores hegemônicos, sejam eles econômicos, sociais ou políticos.

Por fim, deve-se salientar que tanto a metodologia utilizada na pesquisa, como as bibliografias consultadas e citadas na fundamentação teórica satisfizeram integralmente os objetivos propostos pelo trabalho, pois, os resultados obtidos foram e estão em consonância com as colocações teóricas e metodológicas realizadas até o momento, seja por profissionais ligados à Geografia, ou por outros de áreas afins.

\section{Referências}

AMORIM FILHO, O.B. Os Estudos da Percepção como a Última Fronteira da Gestão Ambiental. Anais do II Simpósio Situação Ambiental e Qualidade de Vida na Região Metropolitana de Belo Horizonte e Minas Gerais. Belo Horizonte, ABGE, 1992. 16-20 p.

BARCELOS, V. Educação ambiental: sobre princípios, metodologias e atitudes. Rio de Janeiro: Vozes, 2008. 
BRASIL. Portaria № 204, de 10 de julho de 2013. Estabelece normas e procedimentos para o credenciamento e a autorização de uso para exercício da atividade comercial de condução de visitantes no Parque Nacional do Itatiaia. Disponível em: http://www.icmbio.gov.br/parnaitatiaia/ images/stories/ Normas UP/Portaria condutores 204 10.07.2013.pdf. Acesso em: 15 de dez. 2016.

CAMPOS, R.F.; FILETTO,F. Análise do perfil, da percepção ambiental e da qualidade da experiência dos visitantes da Serra do Cipó (MG). Revista Brasileira de Ecoturismo, São Paulo, v.4, n.1, 2006, 69 -94 p. Disponível em: http://observatorio.wwf.org.br/site media/upload/gestao/documentos/npsF837.t mp.pdf. Acesso em: 22 de nov. 2016

DI TULLIO, A. Biodiversidade e Educação ambiental: A abordagem participativa na construção de uma trilha interpretativa em São José do Rio Pardo - SP. Dissertação (Mestrado em Ciências da Engenharia Ambiental), Escola de Engenharia de São Carlos, Universidade de São Paulo, São Carlos, Brasil: $2005.172 \quad$ p. Disponível em: http://www.teses.usp.br/teses/disponiveis/teses/ disponiveis/18/18139/tde19012006-113913/pt-br.php. Acesso em: 09 de jan. 2017

DOHME, A. V. O valor Educacional dos Jogos. Ed. Vozes, Brasil: 2008. 88p.

FADINI, A.A.B. Sustentabilidade e Identidade Local: Pauta para um Planejamento Ambiental Participativo em Sub - bacias Hidrográficas da Região Bragantina. Tese de Doutorado. Rio Claro: UNESP. 2005. 222 p. Disponível em:https://repositorio.unesp.br/bitstream/handle/11449/104366/fadini aab dr r cla.pdf?sequence $=1$. Acesso em: 13 de nov. 2017

FERREIRA, L.F.; COUTINHO, M.C.B. Educação ambiental em estudos do meio: A experiência do Bioma Educação Ambiental. In: SERRANO, C. (Org.). A educação pelas pedras. São Paulo: Chronos, 2000. 171-188 p.

FIORI, A. Ambiente e Educação: Abordagens Metodológicas da Percepção Ambiental voltadas a uma Unidade de Conservação. Dissertação (Mestrado em Ecologia e Recursos Naturais). Programa de Pós-Graduação do Centro de Ciências Biológicas e da Saúde de Universidade Federal de S. Carlos. S. Carlos, 2002. 95 p. Disponível em: https://repositorio.ufscar.br/bitstream/ handle/ ufscar/1970/DissAF.pdf? sequence=1\&isAllowed=y. Acesso em: 19 de out. 2016

FLORENZANO, T.G.; SANTOS, V.M.N. Difusão do sensoriamento remoto através de projetos escolares. Anais XI SBSR. Belo Horizonte, MG, 05-10 de abril de 2003, Inpe, p. 775-780.

GIL, A.C. Como Elaborar Projetos de Pesquisa. 4a. ed. São Paulo: Atlas, 1991. $176 \mathrm{p}$.

GUIMARÃES, M. A dimensão Ambiental na Educação. Papirus, Campinas, Brasil: 1995. $107 \mathrm{p}$. 
HOEFFEL; J.L.; FADINI, A.B. Percepção Ambiental. In: FERRARO Jr.; L.A. (org.) Encontros e Caminhos: formação de educadoras (es) ambientais e coletivos educadores. Ministério do Meio Ambiente, Departamento de Educação Ambiental Brasília, Brasil: V. 2. 2007. 253-262 p. Disponível em: http://www.mma.gov.br/estruturas/educamb/ arquivos/encontros 2.pdf. Acesso em: 30 de out. 2016

LOUREIRO, C.F.B. Problematizando conceitos em educação ambiental. In: Educação, Ambiente e Sociedade: ideias e práticas em debate. Programa de Comunicação Ambiental/ CST, Instituições de Ensino Superior. Serra: Cia Siderúrgica de Tubarão, Brasil: 2004. 224 p.

LOWMAN, J. Dominando as técnicas de ensino. São Paulo: Atlas, 2004, $309 \mathrm{p}$.

MACHADO, L.M.C.P. A serra do mar Paulista: Um estudo de paisagem valorizada. Tese (Doutorado em Geografia) - Instituto de Geociências e Ciências Exatas, Universidade Estadual Paulista, Rio Claro-SP. 1988.312 p.

MINAYO, M.C.S. O desafio do conhecimento: pesquisa qualitativa em saúde. 4. ed. São Paulo: Hucitec, 1996. 408 p.

MINISTÉRIO DO MEIO AMBIENTE Secretaria de Políticas para o Desenvolvimento Sustentável. Cartilha: Noções básicas para condução de visitantes em áreas naturais. Brasília. Maio 2005. 160 p. Disponível em: http://www.mma.gov.br/estruturas/sedr proecotur/ arquivos/Conducao.pdf

Acesso em: 09 de jan. 2017

NEIMAN, Z. Educação ambiental através do contato dirigido com a natureza. 2007, 136 p. Tese (Doutorado em Psicologia) - Curso de Pós-Graduação em Psicologia, Universidade de São Paulo. Disponível em: http://www.teses.usp.br/teses/disponiveis/47/47132/tde-19062008-085321/ptbr.php. Acesso em: 29 de out. de 2016

NOVAES, S.C. Imagem, magia e imaginação: desafios ao texto antropológico. Mana, Rio de Janeiro, v. 14, n. 2, outubro de 2008. Disponível em:<http://www.scielo.br/scielo.php?script=sci arttext\&pid=S010493132008000 200007\&lng=en\&nrm=isso >. Acesso em: 08 de dez. 2016.

OLIVEIRA, L.I. Percepção da paisagem geográfica: Piaget, Gibson e Tuan. Geografia, Rio Claro, v.25, n.2, 2006. 5-22 p.

RANGEL, I.C.A.; NETO, L.S.; DARIDO, S.C.; GASPARI, T.C.; GALVÃO, Z. O ensino reflexivo como perspectiva metodológica. In: DARIDO, S.C.; RANGEL, I. (Org.). Educação física na escola. Rio de Janeiro: Guanabara Koogan, Coleção Educação Física no Ensino Superior. 2005. 316 p.

SANTOS, M. O espaço do cidadão. São Paulo: Ed. da Universidade de São Paulo, 2007. $176 \mathrm{p}$. 
SAUVÉ, L. Perspectivas Curriculares para la Formación de Formadores em Educación Ambiental. In: Anais do I Foro Nacional de la incorporacón de la perpectiva ambiental en la formación técnica e profesional USALP, México: 2003. 20 p.

SARTORI, M.G.B. Clima e Percepção. Tese (Doutorado em Geografia) Departamento de Geografia/FFLCH/USP, Vol.2. São Paulo, 2000. 192 p.

TELLES, M.Q; ROCHA, M.B.; PEDROSO, M.L.; MACHADO, S.M.C. Vivências integradas com o meio ambiente. São Paulo: Sá Editora, 2002.

TONISSI, R.M.T. Percepção e caracterização ambientais da área verde da microbacia do córrego da Água Quente, São Carlos/ SP como etapas de um processo de educação ambiental. Tese (Doutorado em Ciências da Engenharia Ambiental), Escola de Engenharia de São Carlos, Universidade de São Paulo, São Carlos, Brasil: 2005. 281 p. Disponível em: http://www.teses.usp.br/teses/disponiveis/18/18139/tde-26012006-100606/ptbr.php. Acesso em: 17 de dez. 2016

TUAN, Y.F. Topofilia: Um Estudo da Percepção, Atitudes e valores do Meio Ambiente. Ed. Difel. São Paulo, 1980. 342 p.

TUAN, Y.F. Espaço e lugar: A Perspectiva da Experiência. Ed. Difel. São Paulo, 1983. 248 p.

VASCO, A.P.; ZAKRZEVSKI, S.B.B. The state of the art in research on environmental perception in Brazil. Perspectiva, Erechim. v.34, n.125, 17-28 p., mar. 2010.

VERGARA, S.C. Métodos de pesquisa em administração. São Paulo: Atlas, 2010. 296 p.

ZUBE, E.H.; SELL, J.L; TAYLOR, J.G. Landscape perception: research, application and theory. Landscape Planning, n. 9, 1982. 1 - 33 p.

WHYTE, A.V.T. Guidelines for field studies in environmental perception. Paris: UNESCO, (MAB Technical Notes 5), 1977, 118 p. 